\title{
Erratum to: The minimal clinically important difference in the Oxford knee score and Short Form 12 score after total knee arthroplasty
}

\author{
N. D. Clement ${ }^{1}$ D. MacDonald ${ }^{2}$ A. H. R. W. Simpson ${ }^{3}$
}

Published online: 22 January 2016

(C) European Society of Sports Traumatology, Knee Surgery, Arthroscopy (ESSKA) 2016

\section{Erratum to: Knee Surg Sports Traumatol Arthrosc (2014) 22:1933-1939 DOI 10.1007/s00167-013-2776-5}

Unfortunately, the Fig. 2 was published incorrectly in the original publication.

The lines of correlation between the Oxford Knee Score (dashed line) and the Short-Form 12 Physical Component Score (solid line) with level of satisfaction with function after total knee arthroplasty were incorrect. The gradients were correct but related to other scoring measure, i.e. the gradient for the Oxford Knee Score related to the ShortForm 12 Physical Component Score and vice versa. The means and $95 \%$ confidence intervals are correct as shown in Table 3. An amended figure has now been produced with the corrected lines of correlation (Fig. 2). This amendment does not change the content of the results or the conclusion of the study.

The online version of the original article can be found under doi:10.1007/s00167-013-2776-5.

N. D. Clement

nickclement@doctors.org.uk

1 Royal Infirmary of Edinburgh, Little France, Edinburgh EH16 4SA, UK

2 University of Edinburgh, Little France, Edinburgh EH16 4SA, UK

3 Department of Orthopaedics, Edinburgh University, Little France, Edinburgh EH16 4SA, UK

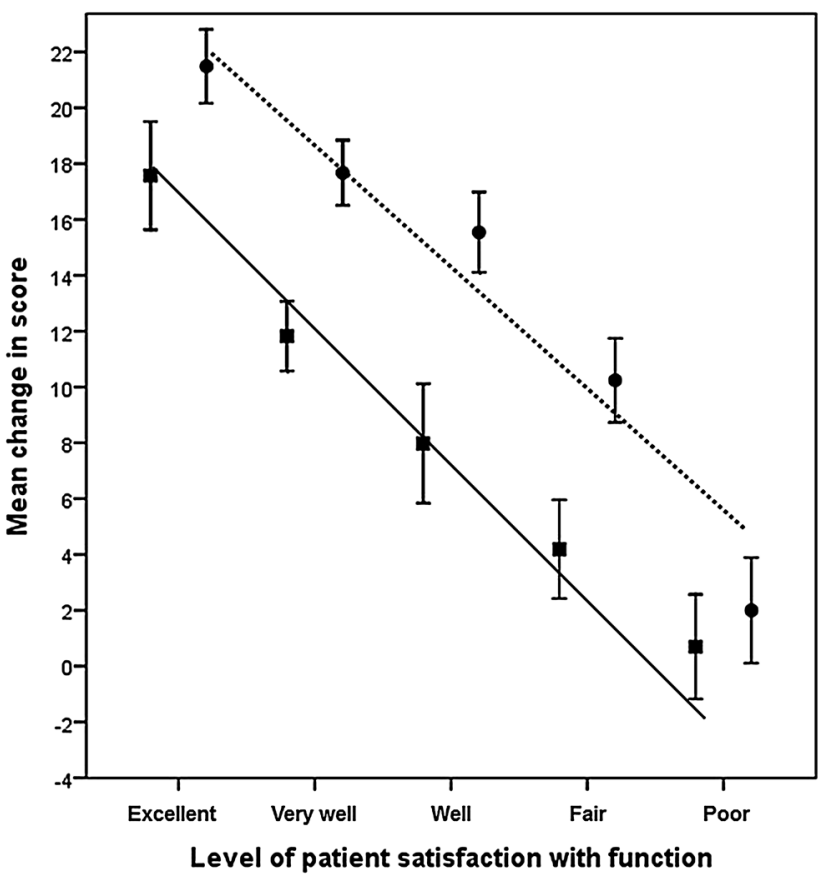

Fig. 2 Change in OKS (circles) and SF-12 PCS (squares) with $95 \%$ $\mathrm{CI}$ at 1 year according to the level of patient satisfaction with function. The correlation between the change in OKS (dashed line) and SF-12 PCS (solid line) and level of satisfaction is illustrated 